\title{
UM CASO DE BILINGÜISMO: A CONSTRUÇÃO LEXICAL, PRAGMÁTICA E SEMÂNTICA
}

\section{A bilingualism case: a lexical, pragmatic and semantics construction}

\author{
Bianca Correia Ferronatto ${ }^{(1)}$, Erissandra Gomes ${ }^{(2)}$
}

\section{RESUMO}

Objetivo: relatar a atuação fonoaudiológica em um caso de bilingüismo precoce. Métodos: relato de caso de paciente do sexo masculino, bilíngüe desde a infância. Encaminhado para atendimento fonoaudiológico, aos 2:4 meses, com a queixa familiar de não se comunicar verbalmente. Descrição através de dados da avaliação e terapia fonoaudiológica ao longo de 2:3 meses de acompanhamento. Resultados: a avaliação fonoaudiológica, baseada na observação informal, constatou presença de formas comunicativas intencionais elementares, caracterizando um atraso simples de linguagem, tendo o bilingüismo como causa. A terapia moldou-se e modificou-se conforme as evoluções do paciente. O paciente obteve crescimento relacionado ao uso do português nos aspectos pragmático, semântico e lexical, atingindo o objetivo principal das intervenções. Conclusão: a fonoterapia mostrou-se efetiva, contribuindo para proporcionar uma melhor qualidade de comunicação e fala ao paciente, essencialmente no que diz respeito ao uso da língua portuguesa.

DESCRITORES: Fala; Multilinguismo; Desenvolvimento da Linguagem

\section{INTRODUÇÃO}

Existem numerosas definições para o termo bilingüismo, uma vez que os critérios para se considerar um sujeito bilíngüe são muito variados ${ }^{1-3}$. A visão atual define o bilíngüe como sendo o falante que possui competência bilíngüe calcada em um sistema reestruturado com propriedades articulatórias e acústicas próprias as quais dependem da interação de muitas variáveis, inclusive da interação dos sistemas fonéticos das duas línguas ${ }^{1}$. $\mathrm{O}$ bilingüismo precoce - bilingüismo de infância ou consecutivo - refere-se à aquisição simultânea de mais de uma língua durante o período de aquisição e desenvolvimento da linguagem primária, incluindo os primeiros cinco anos de vida ${ }^{4}$. Dessa forma, os termos língua nativa ou língua mãe acabam por não se adequar ao contexto da criança bilíngüe de infância, já que, interagindo com mais de uma

(1) Fonoaudióloga da Prefeitura Municipal de Feliz - RS; Especialização em Linguagem pelo CEFAC - Saúde e Educação.

(2) Fonoaudióloga; Docente do Curso de Fonoaudiologia do Centro Universitário Metodista IPA; Mestre em Ciências Médicas: Pediatria pela Universidade Federal do Rio Grande do Sul. língua desde o início da aquisição da linguagem, nenhuma delas pode ser considerada a primeira ou a mais sabida ${ }^{1}$. Nesse sentido, para efeito deste estudo de caso, a definição da criança bilíngüe precoce parece estar mais próxima do que se considera um bilíngüe.

Segundo a literatura, não existem bilíngües perfeitos, pois ninguém consegue ter o mesmo nível de conhecimento e expressão em duas línguas distintas ${ }^{2,3}$. Embora não existam estatísticas precisas, na atualidade a aquisição bilíngüe simultânea constitui fato comum, sendo resultante de inúmeras situações, tais como: casamentos entre membros de grupos lingüísticos diversos, pressões sócio-econômicas, migrações maciças das populações, primeira geração de filhos de imigrantes, dentre outras. A aquisição simultânea de duas línguas é provavelmente muito comum, não devendo ser considerada excepcional quando analisada em confronto com os ambientes de aprendizado da primeira linguagem dispersos culturalmente por todo o mundo ${ }^{4}$.

O desenvolvimento da linguagem bilíngüe em crianças pré-escolares pode divergir do desenvolvimento monolíngüe em aspectos superficiais, mas fundamentalmente os processos são idênticos. As crianças bilíngües empregam as mesmas estratégias de aquisição que as crianças monolíngües, 
sendo, porém, capazes de utilizar seus sistemas lingüísticos em desenvolvimento de maneira diferenciada sob o ponto de vista contextual ${ }^{4}$.

Embora não mantenham dois códigos lingüísticos inteiramente separados, a competência lingüística do bilíngüe não pode ser mensurada com base nos padrões de proficiência dos monolíngues ${ }^{1}$. Nesse sentido, alguns bilíngües cometem erros resultantes das interferências de traços pertencentes a uma língua, enquanto falam ou escrevem outra ${ }^{5}$. Tais erros são considerados marcas daquilo que está sendo re-arranjado na produção lingüística da criança, sendo que a "reorganização" dos erros demonstra uma reflexão da criança sobre a língua ${ }^{6}$. Assim, a possibilidade de efeitos da interação e suas implicações durante a aquisição simultânea de duas línguas têm constituído preocupações essenciais nas pesquisas sobre o desenvolvimento bilíngüe precoce. Da mesma forma, no que se refere às diferenças individuais (idade, estilo cognitivo, personalidade, tipo e proporção de exposição, atitudes e motivação) na aquisição da segunda língua ${ }^{4}$.

No processo inicial de aquisição da linguagem existirão diferenças individuais entre crianças desenvolvendo-se com duas ou mais línguas. $O$ ambiente de input lingüístico mais rico leva a um melhor desenvolvimento das habilidades relevantes para a discriminação fonêmica ${ }^{1}$. Assim, crianças expostas ao ambiente bilíngüe desenvolvem habilidades perceptuais que as habilitarão a distinguir entre as suas duas línguas. Quanto mais cedo as crianças são expostas a duas línguas distintas, maiores serão suas habilidades na competência lingüística e menores suas dificuldades para estabilizar o sistema fonológico dessas línguas ${ }^{7}$. A aquisição bilíngüe não prejudica a consciência fonológica do português ${ }^{8}$. Entretanto, meios desfavoráveis à criança, no período de desenvolvimento crítico da linguagem, podem acarretar atraso ${ }^{9,10}$. Para que a linguagem seja adquirida no tempo esperado o ambiente deve oferecer estimulação suficiente. Nesse sentido, o meio no qual há escassez de estimulação ou exagero na superproteção, torna-se contraproducente ${ }^{9,10}$.

Por fim, o objetivo desse trabalho é descrever a intervenção fonoaudiológica em uma criança exposta à aquisição de duas línguas diferentes, simultaneamente e com dificuldades, durante 0 período de aquisição e desenvolvimento da linguagem. A intervenção fonoaudiológica inclui a avaliação, as etapas do desenvolvimento da terapia e a evolução apresentada pelo paciente.

\section{MÉTODOS}

O fator em estudo é a terapia fonoaudiológica num caso de bilingüismo precoce, incluindo a avaliação e a descrição da terapia realizada durante 2:3 meses, uma vez por semana. O desfecho é a evolução que a criança vai apresentando ao longo da intervenção. O estudo é experimental, não comparado e considera o aspecto analítico dos eventos.

O caso apresentado é de um paciente atendido em consultório multidisciplinar localizado na cidade de Feliz/RS. Os atendimentos fonoaudiológicos foram realizados por uma fonoaudióloga que compreendia e falava o dialeto alemão, característico desta região do estado do Rio Grande do Sul. O paciente foi acompanhado pela fonoaudióloga dos 2:3 meses até 4:6 meses de idade.

A anamnese realizada, de acordo com o protocolo utilizado no Serviço de Fonoaudiologia, coletou os seguintes dados: identificação, queixa principal, resumo das principais intercorrências no período pré, peri e pós-natal, desenvolvimento da linguagem (início das vocalizações, balbucio, primeiras palavras), sociabilidade (cuidadores, com quem convive/contato), antecedentes fisiopatológicos, uso de medicação contínua, uso de outro idioma na residência, rotina diária da criança e tratamentos anteriores. $O$ paciente, sem queixas auditivas, apresentava histórico de uma criança saudável, com potencial intelectual e desenvolvimento cognitivo de acordo com sua faixa etária. Não possuía alterações neurológicas ou de sistema sensório motor oral, tendo sido exposto, desde a nascença, a duas línguas diferentes: o português e o dialeto alemão. Não havia a presença de deficiência mental e/ou indícios de transtornos psicológicos evidentes. A avaliação psicológica e neurológica foi realizada por profissionais especializados.

A análise dos dados da anamnese identificou paciente do sexo masculino, filho único, encaminhado com a queixa de não estar se comunicando verbalmente. Residindo em área rural, era ausente do convívio com outras crianças, permanecendo, durante o dia, sob os cuidados da avó e do tio. Membro de uma família de origem alemã, a qual faz uso do dialeto alemão para se comunicar em casa e na comunidade, usava gestos de apontar e movimentos de cabeça para indicar afirmação ou negação, a fim de se comunicar com a família e buscar o que desejava ou tinha necessidade.

A avaliação da linguagem foi baseada na observação comportamental informal, seguindo tópicos sugeridos por alguns autores ${ }^{11-15}$. Durante as atividades lúdicas que foram propostas, considerou-se as fases de desenvolvimento da linguagem, a função simbólica e os indicadores do desenvolvimento 
no decurso do segundo ano de vida ${ }^{11}$. Não foi possível aplicar uma avaliação objetiva em decorrência das características individuais do paciente.

Nos primeiros contatos entre a terapeuta e o menino, com 2:4 meses de idade, sob avaliação fonoaudiológica, em observação comportamental informal ${ }^{11-15}$, percebia-se logo que era uma criança tímida, com adequado desenvolvimento psicomotor, sistema orofacial sem alterações e atenção auditiva. Entretanto, não compreendia nada do que Ihe era comunicado verbalmente em português e, por isso, possuía dificuldades em permanecer no ambiente terapêutico, apresentando comportamentos atípicos.

Ao longo deste relato de caso apresentar-se-á os resultados, correlacionando-os com os dados da literatura. A presente pesquisa foi avaliada pelo Comitê de Ética e Pesquisa do CEFAC - Saúde e Educação, aprovada sob n86/06 e considerada sem risco. Os pais concordaram com o estudo e assinaram o Termo de Consentimento Livre e Esclarecido.

\section{RESULTADOS}

A avaliação da linguagem, baseada na observação comportamental informal do paciente durante atividades lúdicas ${ }^{11-15}$ constatou, aos 2:6 meses, fase inicial da terapia, que o paciente apresentava muitos procedimentos comunicativos intencionais elementares, envolvendo ações como apontar ou levar a mão do adulto ao objeto desejado, utilizando poucos gestos comunicativos convencionais ${ }^{11}$. Essas constatações foram observadas na sala de espera enquanto a criança interagia com seu familiar, quando se buscava a criança para o atendimento e durante as várias sessões em que a criança solicitava os brinquedos desejados apenas para manipulá-los rapidamente e saciar sua curiosidade.

As únicas produções vocais que fazia eram o riso contextualizado, o choro e o grito em manifestação de contrariedade e protesto. A continuidade desse comportamento permaneceu durante várias sessões semanais. Aos poucos, mostrava-se ao menino que ele poderia utilizar a boca para provocar reações nos objetos (soprar o cata-vento para que girasse, soprar a corneta ou flauta para que emitissem sons) e, assim, obter prazer oral ${ }^{16} \mathrm{e}$ motivação ${ }^{17,18}$. Essa estrutura de sessão, focada na motivação e na atenção conjunta, foi mantida durante aproximadamente 3 meses e durava, em média, 15 minutos. O paciente tinha liberdade para manipular qualquer brinquedo e fazia-o de forma sensório-motora, de acordo com sua faixa etária ${ }^{19}$.
Após 4 meses de fonoterapia, começou a demonstrar interesse, durante as atividades lúdicas, pela carreta com animais (instrumento típico da região) em miniatura. Nesse momento, ainda sem trocas verbais comunicativas, começou a usar esse brinquedo como forma de interação contextualizada ${ }^{17}$, compartilhando a atividade com o terapeuta, seguindo os preceitos do socio-interacionismo ${ }^{13,17,20}$, modificando-se o enfoque da terapia e o material usado. Na sessão terapêutica, fazia-se referência aos animais chamando-os de "bichos", nomeando-os em português e depois correlacionando com o alemão gramatical. Produzia-se, também, a onomatopéia dos mesmos. Nesse momento, o paciente começou a gostar e a permanecer mais tempo nas sessões, as quais começavam a durar 30 minutos, estabelecendo vínculo terapêutico forte e imitando alguns dos sons que eram produzidos, tornando evidente o papel da imitação diferida e da fala imitativa ${ }^{11,17}$. Surgia uma fala rudimentar.

Ao final do primeiro ano de terapia, fazendo uso de livros infantis com fotos de animais, ou de desenhos no quadro negro, era solicitada ao menino a nomeação das figuras, obtendo-se como resposta, para todos os animais: "bicho!". Apareciam as primeiras palavras com múltiplas significações ${ }^{11}$. Em algumas situações, a criança produzia frases com várias palavras em alemão rudimentar, como quem quer contar algo. Esses momentos eram interpretados como funcionais, no intuito de estimular suas produções vocais.

Decorridos 1:6m de terapia, quando já estava com 3:9m de idade, a queixa da família passou a ser a de que o menino falava (dialeto alemão), mas como não se fazia compreender, ficava bravo e agressivo.

Depois de orientar, sem sucesso, a família a colocá-lo em contato com outras crianças ou numa creche ${ }^{11} \mathrm{e}$ a não atender prontamente suas manifestações gestuais, modificou-se a conduta terapêutica. $\mathrm{O}$ atendimento passou a ser feito conjuntamente com uma menina que falava o português e entendia o alemão, já que residia na mesma região que o paciente, e que possuía apenas algumas alterações em aspectos fonológicos. O paciente começou a diversificar o material que utilizava para brincar, fazendo várias trocas de brinquedos durante as sessões terapêuticas e competindo com sua parceira nos jogos que estimulavam a ampliação de vocabulário. Passou a usar mais intensamente a questão da imitação e da interação com a menina. Demonstrava interesse pelos lápis de cor e pela escrita (desenho). Ao final de 2:4 meses de terapia, seu vocabulário em português havia ampliado, já conseguindo nomear alguns animais. Usava muitas frases em alemão, agora inteligíveis e com alguns 
elementos em português. Começaram a aparecer as primeiras dificuldades de fala com o desenvolvimento da língua portuguesa.

Houve evolução do paciente com relação aos aspectos lingüísticos de pragmática, semântica e léxico. A pragmática desenvolveu-se à medida que foram criadas situações terapêuticas que provocavam uma necessidade de se comunicar para obter algo, atrair a atenção das pessoas ou manter a atenção conjunta. Esse desenvolvimento ocorreu, principalmente, com a inserção de um terceiro sujeito na sessão terapêutica. O léxico e a semântica desenvolveram-se simultaneamente quando a criança era envolvida em atividades lúdicas que empregavam brinquedos de seu interesse e figuras.

A Tabela 1 relaciona, de forma resumida, a evolução dos aspectos pragmáticos ao longo do processo terapêutico com a idade cronológica do paciente. Enquanto a Tabela 2 correlaciona as características lexicais e semânticas com a respectiva idade do paciente durante o período em que esteve em acompanhamento fonoaudiológico.

\section{Tabela 1 - Evolução terapêutica da função comunicativa do paciente}

\begin{tabular}{l|l}
\hline Idade & \multicolumn{1}{c}{ Características pragmáticas } \\
\hline 2 anos e & $\begin{array}{l}\text { Comunicação intencional instrumental e de protesto por meio de gestos não simbólicos } \\
\text { elementares e convencionais }\end{array}$ \\
\hline 3 anos & $\begin{array}{l}\text { Comunicação intencional instrumental e de protesto, presença de funções comunicativas } \\
\text { interativa e informativa restritas, por meio de gestos não simbólicos convencionais e gestos } \\
\text { simbólicos }\end{array}$ \\
\hline 4 anos & $\begin{array}{l}\text { Comunicação intencional plurifuncional, restrita participação em atividade dialógica } \\
\text { relacionada ao contexto imediato, por meios verbais e gestos simbólicos }\end{array}$ \\
\hline 4 anos e & $\begin{array}{l}\text { Comunicação intencional plurifuncional, ampla participação em atividade dialógica } \\
\text { relacionada ao contexto imediato e não imediato, por meios verbais e gestos simbólicos }\end{array}$ \\
\hline
\end{tabular}

Tabela 2 - Evolução terapêutica da expressão verbal do paciente

\begin{tabular}{|c|c|}
\hline Idade & Características lexicais e semânticas \\
\hline $\begin{array}{l}2 \text { anos e } \\
6 \text { meses }\end{array}$ & Somente vocalizações não articuladas \\
\hline 3 anos & Vocalizações não articuladas e articuladas com entonação da língua alemã \\
\hline $\begin{array}{l}3 \text { anos e } \\
6 \text { meses }\end{array}$ & $\begin{array}{l}\text { Imitação verbal intensa de onomatopéias contextualizada, primeiras palavras com múltiplos } \\
\text { significados em português; intenso jargão melódico em alemão }\end{array}$ \\
\hline 4 anos & $\begin{array}{l}\text { Uso de palavras isoladas com múltiplas significações e início da nomeação de objetos } \\
\text { contextualizados em português; enquanto produzia enunciados de } 2 \text { ou } 3 \text { palavras em } \\
\text { alemão }\end{array}$ \\
\hline $\begin{array}{l}4 \text { anos e } \\
6 \text { meses }\end{array}$ & $\begin{array}{l}\text { Enunciados de dois elementos e amplo uso da nomeação de objetos por imitação em } \\
\text { português; construção de frases com } 3 \text { ou mais palavras em alemão com eventual } \\
\text { interferências da língua portuguesa, ou seja, produzia frases com muitas palavras em } \\
\text { alemão e poucas em português na mesma construção frasal. }\end{array}$ \\
\hline
\end{tabular}

\section{DISCUSSÃO}

A terapia baseou-se no sócio-interacionismo ${ }^{13,17}$ com atividades lúdicas, envolvendo o brincar e o jogar. Estudos apontam para a importância das atividades lúdicas na construção do conhecimento, no desenvolvimento cognitivo e na formação social da criança. A criança que brinca experimenta frustrações, alegrias e aprende a ter limites. O papel do adulto na brincadeira consiste em favorecer um ambiente facilitador de descobertas e crescimento ${ }^{21,22}$. A evolução no modo de brincar está relacionada com o desenvolvimento cognitivo e lingüístico da criança ${ }^{12,19} \mathrm{com}$ sua faixa etária ${ }^{22}$. Quando se está entusiasmado com a brincadeira, a linguagem verbal torna-se mais fluente ${ }^{21}$.

A linguagem se estabelece quando a criança domina três aspectos importantes: o pragmático, que corresponde à intenção social da comunicação; 
o semântico, que é o conteúdo a ser comunicado; e o gramatical, que se subdivide em sintaxe, morfologia e fonologia. A sintaxe diz respeito às regras que regem as sentenças que falamos; a morfologia, às menores unidades significativas de nossa língua; e a fonologia, aos sons ou fonemas ${ }^{23}$. Devido a esses fatores, foram enfocados no presente estudo de caso os aspectos pragmáticos, lexicais e semânticos. A criança que possui dificuldades de expressão e produção verbal pouco inteligível pode ter como origem de seu problema déficits de vocabulário que restringem suas produções de fala e déficits gramaticais que a impedem de se expressar de acordo com as regras implícitas da comunicação ${ }^{16}$.

As crianças com atraso simples de linguagem são geralmente normais no plano afetivo, intelectual, neurológico e auditivo, no entanto, falam menos em quantidade e qualidade. Tais crianças não apresentam problemas para imitar e sua comunicação costuma ser realizada com muitos gestos e onomatopéias, porquanto sua linguagem receptiva é bem superior à expressiva ${ }^{10,11}$. As causas podem ser: o ambiente sem estimulação ou com estímulos impróprios, o bilingüismo (quando há presença de uma segunda língua sem o domínio de uma primeira), a relação mãe-filho inadequada, fatores hereditários, dentre outras ${ }^{10}$.

A evolução no desenvolvimento lingüístico do sujeito da pesquisa ocorreu da seguinte forma: aos $30 \mathrm{~m}$ de idade apresentava formas comunicativas intencionais elementares (apontar o objeto, levar a mão do adulto ao local desejado) esperadas para a idade de $8-12 \mathrm{~m}^{11}$; aos $36 \mathrm{~m}$ continuava com essa conduta, tendo incorporado outras que seriam apropriadas a uma criança com cerca de $24 \mathrm{~m}$ (condutas instrumentais e uso convencional dos objetos) ${ }^{11}$; por volta dos $48 \mathrm{~m}$ começou a usar palavras com múltiplas significações, próprias para uma criança entre $18-24 \mathrm{~m}^{11}$, enquanto já formava frases rudimentares em alemão. Aos 4:6m já incorporava enunciados de dois elementos e novas palavras com a omissão de letras no português, comportamento lingüístico aceitável para crianças de $24-36 \mathrm{~m}^{11}$. Nessa época, apareceram frases fluentes em alemão. Ao final da terapia, a criança já havia aumentado sua expressão verbal, fazendo uso ora do dialeto alemão, ora da língua portuguesa para se comunicar. Também se socializou, interagindo com pessoas estranhas e aprendendo certos limites sociais, como guardar o brinquedo após usá-lo.

Há um estudo que se refere à intervenção precoce como efetiva, quando se busca amenizar as conseqüências ou prejuízos que situações específicas geram no curso evolutivo da linguagem. As dificuldades na evolução da expressão verbal podem persistir em função das características da criança, da família ou do meio ${ }^{11}$. Características individuais do paciente fizeram com que ele demorasse muito para estabelecer vínculo e engajar-se na terapia, o que prolongou o tempo de atendimento. No momento que ele começou a participar ativamente, evoluiu rapidamente na expressão verbal, conseguindo equiparar-se a uma criança de sua faixa etária, comprovando a importância e eficiência das intervenções precoces.

A resistência da família em aderir às orientações para usar somente o idioma português com o paciente, retardando também o tempo de terapia, é explicada através de estudos sobre a preservação da língua símbolo da origem de uma família. Eleger a língua que representa a origem de um grupo familiar, de forma consistente, como língua primordial no espaço da casa, parece ser a maneira mais eficiente de contribuir para o desenvolvimento da competência comunicativa. Essa postura é perfeitamente visível em famílias de cultura tradicional. A imposição do uso da língua de origem em casa atende a duas necessidades expressas pelos adultos: a primeira refere-se ao desejo de assegurar a manutenção da identidade e do vínculo com a terra de origem; a segunda manifesta a garantia de preservar a autoridade paterna/materna na dinâmica das relações interpessoais no contexto familiar, mantendo a estabilidade na hierarquia de poder entre as gerações ${ }^{24}$.

O desenvolvimento lexical sofre interferência do ambiente lingüístico e das condições sócio-econômico-culturais da criança ${ }^{25}$. O input lingüístico dos familiares e as habilidades cognitivas da criança podem contribuir para seu crescimento ${ }^{26}$, uma vez que, antes de ocorrer a explosão do vocabulário, quase metade das palavras usadas pelas crianças são de nomes de objetos familiares ${ }^{27}$. $O$ paciente do estudo iniciou suas produções verbais em português na terapia, a partir da nomeação de objetos que representavam sua realidade, acompanhados de seus respectivos significados, denunciando que seu ambiente e seu input lingüístico familiar não eram suficientemente estimulantes nesse sentido e, por isso, suas evoluções eram lentas. Os aspectos pragmáticos da linguagem são desenvolvidos à medida que a criança apresenta uma razão ou motivação para se comunicar, quando surgem situações que provocam uma necessidade comunicativa ${ }^{23}$ e quando ocorre a satisfação dessa necessidade, após o uso da expressão verbal. A terapia foi conduzida de acordo com esses aspectos alcançando, então, resultados positivos.

O paciente em questão expressava-se melhor em alemão do que em português ao final do período de terapia relatado. Assimetrias dessa natureza podem revelar diferenças de exposição e de 
possibilidades de uso de uma língua em relação à outra $^{2}$. Isso sugere que a melhor performance em alemão pode significar que não houve exposição suficiente ao português até o momento e que o uso desse idioma ainda está muito pouco presente na rotina desta criança.

Dificuldades afetivas e sociais são freqüentemente encontradas em indivíduos que não conseguem falar ou se expressar de modo a serem compreendidos ${ }^{11}$, o que acaba gerando constante frustração. A frustração gera raiva e agressão, o que foi percebido nos primeiros contatos com o paciente. A agressividade por meio de ataque, protesto ou rebeldia não só faz com que o paciente minimize, temporariamente, sua dificuldade, como também o faz desfrutar da vingança em reconhecer pontos fracos nos outros, atacando aqueles que tornam sua realidade desagradável ${ }^{16}$. Talvez o mais frustrante de tudo seja a incapacidade de utilizar a fala como meio de expressão de si mesmo ${ }^{16}$. Nesses casos, ao invés de contestar diretamente a raiva do paciente, a literatura sugere que o terapeuta, sem exigir que o paciente fale, solicite sua ajuda para realizar uma tarefa da qual ele é capaz ${ }^{16}$. De forma semelhante agiu-se com o paciente desse estudo, oportunizando atividades orais lúdicas estimulantes.
Independente das diversas concepções sobre inteligência e sua relação com a aprendizagem, fica evidente que primeiro o indivíduo deve estar motivado a aprender algo. Estimular a motivação é aproveitar ao máximo as potencialidades de cada um ${ }^{18}$. Exatamente por isso, a motivação foi um dos principais focos na terapia realizada.

\section{CONCLUSÃO}

O tratamento fonoaudiológico demonstrou eficácia: houve aumento significativo nas trocas verbais entre a criança e seus interlocutores e ampliação do léxico, acompanhado do respectivo conteúdo semântico das palavras. Nos aspectos sociais, verificou-se melhora na qualidade da interação paciente-terapeuta e diminuição das atitudes de rebeldia/agressividade.

A partir desse estudo é possível perceber a importância da intervenção fonoaudiológica precoce nas crianças com atraso simples de linguagem e expostas a duas línguas distintas desde o início de seu desenvolvimento, como forma de prevenir graves dificuldades que poderiam surgir com o início da escolarização, caso a criança não recebesse atendimento prévio.

\begin{abstract}
Purpose: to report on speech therapy performance in a precocious bilingualism case. Methods: report of a male patient case, bilingual since his childhood. Referred to a speech therapy attendance, with the age of two years and four months, with a familiar complaint about his non-verbally communication. Description through assessment data and speech language therapy for three months. Results: the speech language therapy assessment, based on informal observation, found out some elementary intentional aspects of communication forms, characterizing a simple lateness of language, having the bilingualism as a cause. The therapy adapted and changed itself according to the patient evolutions. The patient gained development related with the use of Portuguese in pragmatic, semantics and lexical aspects, achieving the main purpose of interventions. Conclusion: the speech language therapy was efficient, contributing to afford a better quality of communication and speech to the patient, essentially with regards to the use of Portuguese language.
\end{abstract}

KEYWORDS: Speech; Multilingualism; Language Development

\section{REFERÊNCIAS}

1. Rocca PDA. O desempenho de falantes bilíngües: evidências advindas da investigação do VOT de oclusivas surdas do inglês e do português. Delta 2003; 19(2):303-28.

2. Oppenheimer F, Ávila CRB. Influence of bilingualism in usual word designation in naming tasks: a study with brazilian preschoolers. Pró-fono. 2004; 16(4):169-78.
3. Berruecos P. Bicultura y bilingüismo. Rev Fac Med UNAM. 1990; 33(1):66-73.

4. Genesse F. Desenvolvimento da linguagem bilíngüe em crianças pré-escolares. In: Bishop D, Mogford K. Desenvolvimento da linguagem em circunstâncias excepcionais. Rio de Janeiro: Revinter; 2002. p. 73-98.

5. Mackey WF. A typology of bilingual education. Foreign Lang Ann. 1970; 3:596-608. 
6. Figueira RA. O erro como dado de eleição nos estudos de aquisição da linguagem. In: Castro MFP. O método e o dado no estudo da linguagem. Campinas: UNICAMP; 1996. p. 55-86.

7. Bosch L, Sebastián-Gallés N. Native-language recognition abilities in 4-month-old infants from monolingual and bilingual environments. Cognition. 1997; 65(1):33-69.

8. Araújo FP, Lindenbaum J, Figueiredo FV, Chiappetta ALML. A consciência fonológica do português na aquisição simultânea de duas línguas. Rev CEFAC. 2006; 8(1):15-9.

9. Carvalho JF, Homem FCB. A influência do meio na aquisição da linguagem. Fono Atual. 2001; 4(17):14-6.

10. Jakubovicz R. Atraso de linguagem: diagnóstico pela média dos valores da frase. Rio de Janeiro: Revinter; 2002. 199 p.

11. Zorzi JL. Aspectos básicos para a compreensão, diagnóstico e prevenção dos distúrbios de linguagem na infância. Rev CEFAC. 2000; 2(1):11-5.

12. Zorzi JL. A intervenção fonoaudiológica nas alterações de linguagem infantil. Rio de Janeiro: Revinter; 1999. 139 p.

13. Hage SR. Avaliando a linguagem na ausência da oralidade: estudos psicolingüísticos. São Paulo: EDUSC; 1997. 125 p.

14. Chiari BM, Basílio CS, Nakagwa EA, Cormedi MA, Silva NSM, Cardoso RM et al. Proposta de sistematização de dados da avaliação fonoaudiológica através da observação de comportamentos de crianças de 0-6 anos. Pró-fono. 1991; 3(2):29-36.

15. Shippley KG, McAfee JG. Assessment in speech-language pathology: a resource manual. California: Singular. 1992. 424 p.

16. Van Riper C, Emerick L. Correção da linguagem: uma introdução à patologia da fala e à audiologia. 8 . ed. Porto Alegre: Artes Médicas; 1997. 445 p.
17. Bock AMB, Furtado O, Teixeira MLT. A psicologia do desenvolvimento. In: Bock AMB, Furtado $O$, Teixeira MLT. Psicologias: uma introdução ao estudo da psicologia. 6. ed. São Paulo: Saraiva; 1994. p. 80-95.

18. Serapompa MT. Avaliação da aprendizagem escolar. Rev CEFAC. 1999; 1(2):86-91.

19. Piaget J. O nascimento da inteligência na criança. Rio de Janeiro: Zahar; 1970. 378 p.

20. Moraes ZR. Distúrbios de aprendizagem. In: Goldfeld M. Fundamentos em fonoaudiologia: linguagem. Rio de Janeiro: Guanabara Koogan; 1998. p. 39-51.

21. Novaes APDC. A importância do jogo e do brincar em terapia fonoaudiológica. Rev CEFAC. 2000; 2(2):45-54.

22. Fernandes LH. O brincar na visão do adulto. Rev CEFAC. 2002; 4(1):11-5.

23. Zorzi JL. Diferenciando alterações de fala e linguagem. In: Marchesan IQ. Fundamentos em fonoaudiologia: aspectos clínicos da motricidade oral. Rio de Janeiro: Guanabara-Koogan; 1998. p. 59-74.

24. Mota KS. Aulas de português fora da escola: famílias imigrantes brasileiras, esforços de preservação da língua materna. Cad CEDES. 2004; 24(63):149-63.

25. Torres MLGM, Maia HÁ, Perissinoto J, Assencio-Ferreira VJ. Descrição do léxico expressivo de crianças aos 5 anos de idade. Rev CEFAC. 2002; 4(3):241-51.

26. Benedict H. Early lexical development; comprehension and production. J Child Lang. 1979; 6(2):183-200.

27. Goldfield BA, Reznick JS. Early lexical acquisition: rate, content, and the vocabulary spurt. J Child Lang. 1990; 17(1):171-83.

\section{RECEBIDO EM: 16/01/2007 \\ ACEITO EM: 04/02/2008}

Endereço para correspondência:

Rua Barão de Teffé, 130/302

Porto Alegre - RS

CEP: $90160-150$

Tel: (51) 91131359

E-mail: bcf.ez@terra.com.br 